\title{
Novel lecithin-integrated liquid crystalline nanogels for enhanced cutaneous targeting of terconazole: development, in vitro and in vivo studies
}

This article was published in the following Dove Press journal:

International Journal of Nanomedicine

25 October 2016

Number of times this article has been viewed

\author{
Yosra SR Elnaggar ${ }^{1,2}$ \\ Sara M Talaat ${ }^{1}$ \\ Mohammed Bahey-El-Din ${ }^{3}$ \\ Ossama Y Abdallah' \\ 'Department of Pharmaceutics, \\ Faculty of Pharmacy, Alexandria \\ University, ${ }^{2}$ Department of \\ Pharmaceutics, Faculty of Pharmacy \\ and Drug Manufacturing, Pharos \\ University in Alexandria, ${ }^{3}$ Department \\ of Microbiology and Immunology, \\ Faculty of Pharmacy, Alexandria \\ University, Alexandria, Egypt
}

\begin{abstract}
Terconazole (Tr) is the first marketed, most active triazole for vaginal candidiasis. Owing to poor skin permeation and challenging physicochemical properties, Tr was not employed for the treatment of cutaneous candidiasis. This is the first study to investigate the relevance of novel lecithin-integrated liquid crystalline nano-organogels (LCGs) to improve physicochemical characteristics of $\mathrm{Tr}$ in order to enable its dermal application in skin candidiasis. Ternary phase diagram was constructed using lecithin/capryol 90/water to identify the region of liquid crystalline organogel. The selected organogel possessed promising physicochemical characteristics based on particle size, rheological behavior, $\mathrm{pH}$, loading efficiency, and in vitro antifungal activity. Microstructure of the selected organogel was confirmed by polarized light microscopy and transmission electron microscopy. Ex vivo and in vivo skin permeation studies revealed a significant 4.7- and 2.7-fold increase in the permeability of Tr-loaded LCG when compared to conventional hydrogel. Moreover, acute irritation study indicated safety and compatibility of liquid crystalline organogel to the skin. The in vivo antifungal activity confirmed the superiority of LCG over the conventional hydrogel for the eradication of Candida infection. Overall, lecithin-based liquid crystalline organogel confirmed its potential as an interesting dermal nanocarrier for skin targeting purpose.
\end{abstract}

Keywords: terconazole, liquid crystalline, organogel, skin targeting, skin mycosis

\section{Introduction}

Since the early 1980s, the susceptibility and sensitivity to fungal infection have increased significantly in terms of frequency and also as a cause of morbidity and mortality. ${ }^{1-3}$ Among different fungal infections, the occurrence of superficial mycotic infections has risen in the last decades, now affecting $>20 \%-25 \%$ of the world's population. In addition, cutaneous candidiasis caused by Candida species became the most prevalent superficial mycosis affecting most of human beings, ${ }^{4}$ particularly immuno-compromised ones. ${ }^{5,6}$

Treatment of Candidal infections is still challenging and is restricted to a small number of antifungal drugs, mainly azole derivatives. ${ }^{6-8}$ However, their application is usually limited due to increase in the incidence of azole resistance ${ }^{9}$ and other toxicity issues. ${ }^{7,10}$ Moreover, many newer antifungal agents have limitations in terms of their spectrum of activity, pharmacokinetics, and drug-drug interactions besides their uncommon toxicities related to their long-term use. ${ }^{11}$ Therefore, looking for preexisting antifungals that have not been investigated yet for cutaneous candidiasis may arise as a possible surrogate to overcome the drawbacks of azoles and other new antifungal agents. Thus, the first scope of our study was to investigate an old synthetic
Correspondence: Yosra SR Elnaggar

Department of Pharmaceutics, Faculty of Pharmacy, Alexandria University, PO Box 21521, I Khartoum Square, Alexandria, Egypt

Tel +20 I I4759 I065

Fax +2034873273

Email yosra_pharm@yahoo.com 
triazole vaginal antifungal known as terconazole (Tr) for the eradication of cutaneous candidiasis.

Tr was the first marketed triazole antifungal with a molecular weight of $532.47 \mathrm{Da}^{12,13}$ It is approved by the Food and Drug Administration for the treatment of vulvovaginitis (moniliasis). ${ }^{14}$ It is a broad-spectrum antifungal agent against different fungi such as yeasts and dermatophytes. In addition, $\operatorname{Tr}$ was found to be one of the most active azoles against Candida species, using the relative inhibition factor methodology. ${ }^{15}$ It outperforms imidazoles in terms of activity and curing rates for the treatment of vulvovaginal candidiasis. ${ }^{16}$ It is still used as an effective first-line treatment against moniliasis particularly in cases resistant to other drugs. ${ }^{17,18}$ Nevertheless, its potential in the treatment of skin mycosis has not been so far investigated, which will be first considered in this work.

Topical treatment of superficial fungal infections has various advantages over oral route such as targeting the site of infection, reduction of systemic side effects, enhancing the efficacy of treatment, and high patient compliance. ${ }^{19}$ The current available antifungal drugs are commercially available in conventional dosage forms including creams, ointments, gels, and lotions. The major drawback of these formulations is that most of them suffer from restricted drug delivery across the skin, resulting in therapeutic failure. ${ }^{20}$ On the other hand, several excipients are often used in other formulations for enhancing drug permeation through stratum corneum (SC) such as Azone ${ }^{21,22}$ and dimethyl sulfoxide. ${ }^{23}$ These excipients cause disruption to the SC layers resulting in the penetration of antifungal drug into the deeper skin layers and, unfortunately, into blood circulation causing systemic side effects. ${ }^{24}$ Therefore, in order to overcome obstacles faced by conventional topical formulations, new formulation approaches have been investigated.

In fact, as our research team believes in the significance of nanotechnology to achieve the unreachable goals, therefore, the team has developed different nanocarriers to enhance the efficacy of many bioactives. ${ }^{25-27}$ Among them, lipid-based nanocarriers were one of our interests and have been utilized in different applications. ${ }^{28,29}$ In recent years, attentions have been given toward lipid-based delivery systems as they seem to be well-preferred topical drug delivery systems. ${ }^{30}$ They are considered attractive nanocarriers over polymeric nanocarriers because of the unique properties of lipids such as their physiochemical diversity, biocompatibility, and safety. ${ }^{31,32}$ Among different types of lipid delivery systems, phospholipid (PL)- and lecithin-based organogels were found to be intriguing. In addition to being natural and nonallergic molecules, PLs are also recognized as permeation enhancers because of their similarity to bio-membrane composition. Among different types of lecithin organogels, lecithin-based liquid crystalline nano-organogels (LCGs) are considered promising topical nanocarriers because of their thermodynamical stability, considerable solubilizing capability for both oil and water soluble compounds, and very low skin irritation potential. ${ }^{33,34}$ They have the potential to control the drug release, low toxicity, and versatility in applications across a range of administration regimes.

Therefore, the present study is the first to investigate the dermal potential of the known vaginal antifungal Tr via elaboration of novel Tr-loaded lecithin-based liquid crystalline organogel. Full in vitro appraisal of the nanogels would be carried out and supported by in vivo antifungal investigations and ex vivo and in vivo permeation studies.

\section{Materials and methods Materials}

Tr was kindly provided by Medizen Pharmaceutical Industries Co. (Alexandria, Egypt). Capryol 90 ${ }^{\circledR}$ (propylene glycol [PG] monocaprylate, hydrophilic lipophilic balance [HLB] =6) was a gift from Gattefosse Co. (Lyon, France). Phospholipon $90 \mathrm{G}$ (soybean lecithin of $\sim 90 \%$ phosphatidylcholine) was obtained from Lipoid GmbH (Ludwigshafen, Germany). Hydroxypropyl methylcellulose $\mathrm{K} 4 \mathrm{~m}$ was obtained from Al Amriya Pharmaceutical Industries Co. (Alexandria, Egypt). Sabouraud dextrose agar was obtained from Oxoid Limited (Basingstoke, Hampshire, UK). All other chemicals and reagents used were of analytical grade.

\section{Construction of ternary phase diagram}

In order to determine the concentration range of the system components (water/capryol/lecithin) that form lyotropic LCG, a ternary phase diagram was constructed using a water titration technique. For the titration process, a homogeneous mixture of capryol (CAP) and lecithin (G90) at varied weight ratios was slowly titrated using increasing amount of distilled water and was stirred at room temperature for a sufficient time in order to obtain equilibrium. ${ }^{35}$ The mixtures were then checked visually, and slight hazy samples of high viscosity were additionally checked through the polarizing light microscope ${ }^{36}$ (Model CX 31; Olympus, Hamburg, Germany). Appearance of turbidity was taken as end point. Because only region of liquid crystals was of our interest, no intention existed for the identification of other regions of the ternary phase diagram in detail.

\section{Preparation of Tr-loaded LCG (Tr-LCG)}

Based on ternary phase diagram, a mass ratio of 1:1.2 lecithin to CAP was selected for the preparation of the organogel. 
LCG was prepared by first dissolving $\operatorname{Tr}(1 \% \mathrm{w} / \mathrm{w})$ in CAP oil. This solution was heated up to $40^{\circ} \mathrm{C}$ and then the preweighed lecithin was added to the solution and sonicated at $50^{\circ} \mathrm{C}-55^{\circ} \mathrm{C}$ until there is a complete dissolution of lecithin to obtain a homogeneous mixture of lecithin in $\mathrm{Tr}-$ oil solution. To this mixture, distilled water was titrated through a micropipette upon stirring with a magnetic stirrer (IKA Labortechnik, Germany) until the viscosity of the system was increased. The samples were then allowed to cool down and set aside to obtain homogenous gels at room temperature.

\section{Preparation of Tr-loaded conventional gel}

Tr-loaded conventional hydroxy propyl methyl cellulose (HPMC)-based hydrogel was prepared as a control gel for comparison with lecithin organogel. A batch of $25 \mathrm{~g}$ gel was prepared by first dispersing $250 \mathrm{mg}$ of $\operatorname{Tr}(1 \% \mathrm{w} / \mathrm{w})$ in $24 \mathrm{~mL}$ of distilled water under magnetic stirring at $50^{\circ} \mathrm{C}$, and then $1 \mathrm{~g}$ of HPMC was added portion wise. The mixture was then allowed to cool down and set aside to obtain gel at room temperature.

\section{Physicochemical characterization of liquid crystalline organogel Organoleptic characteristics}

The physical evaluation of pharmaceutical formulation is a critical step as it is directly related to patient acceptance. The prepared organogel was tested for color, odor, texture, phase separation, and the feel upon application (grittiness and greasiness). These features were also checked during stability studies. ${ }^{34}$

\section{Determination of $\mathrm{pH}$}

The $\mathrm{pH}$ of all prepared formulations was determined by $\mathrm{pH}$ papers at room temperature.

\section{Viscosity measurement}

The viscosity of selected Tr-loaded lecithin organogel and its placebo gel was evaluated using a cone and plate Brookfield viscometer (Model DV2T; Brookfield Engineering Laboratories, INC., USA) with a spindle 40. The sample was placed between the gap of the cone and plate, and the gap was closed gradually. ${ }^{37}$ Then the sample was subjected to a dynamic shear rate ranging from 7.5 to $45 \mathrm{~S}^{-1}$ (1-6 rpm) where shear stress and viscosity were measured. All the measurements were performed at isothermal condition at room temperature $\left(25^{\circ} \mathrm{C} \pm 2^{\circ} \mathrm{C}\right)$.

\section{Content uniformity}

For the determination of drug content homogeneity, $50 \mathrm{mg}$ of the organogel formulation was diluted with appropriate amount of methanol, and the mixture was shaken to get a clear solution. The concentration of $\operatorname{Tr}$ was determined by a validated UV spectrophotometer at $\lambda=243 \mathrm{~nm}$. The placebo formulation was taken as blank after appropriate dilution with methanol. The drug content was calculated from the calibration curve and expressed as: ${ }^{38}$

$$
\text { Drug content } \%=\frac{\text { Actual drug content }}{\text { Theoritical drug content }} \times 100
$$

\section{Polarized light microscopy (PLM)}

A drop of the slight hazy samples prepared during phase diagram study was put on a slide under a cover slip and was observed through the polarizing microscope. ${ }^{39}$ The structure of the medicated and placebo LCG samples was examined by a polarizing microscope (Model CX 31; Olympus) using a magnification of $100 \times .^{35}$

\section{In vitro antifungal activity}

The antifungal activity of $\operatorname{Tr}$ from LCG against Candida albicans (ATCC ${ }^{\circledR}$ 2091) was determined by adopting the cup plate method reported by Ozcan et $\mathrm{al}^{40}$ with slight modifications. The mean inhibition zone was calculated, and the value was taken as an indicator for the antifungal activity.

\section{Fungal inoculum}

Overnight culture of C. albicans was diluted with $0.9 \%$ sterile saline to obtain cultures containing $10^{6}$ colony-forming units $(\mathrm{CFU}) / \mathrm{mL}$ of the microorganism.

\section{Plate diffusion method}

Tr-loaded LCG was compared to its placebo sample, and HPMC gel of $\operatorname{Tr}(1 \% \mathrm{w} / \mathrm{w})$ was also enrolled in the study as a positive control. Petri dishes of $20 \mathrm{~mL}$ Sabouraud dextrose agar were seeded with $200 \mu \mathrm{L}$ of the Candida inoculum $(1 \% \mathrm{v} / \mathrm{v})$. The plates were left to dry at room temperature for $15 \mathrm{~min}$. Then, wells were cut out where $70 \mathrm{mg}$ of each gel formulation was placed into each well. The plates were incubated at $37^{\circ} \mathrm{C} \pm 0.1^{\circ} \mathrm{C}$ for $24 \mathrm{~h}$. The results were recorded by measuring the inhibition zones around the wells. ${ }^{40}$ All the determinations were made in triplicate for each formulation.

\section{In vitro drug release study}

In vitro drug release was carried out according to the dialysis bag method reported by Gupta et $\mathrm{al}^{7}$ and Kumar et al, ${ }^{41}$ with a slight modification. Tr release from LCG was compared to its release from HPMC-based hydrogel using the same final concentration and the same sink conditions. Tr solution in PG $(1 \% \mathrm{w} / \mathrm{v})$ was used as a control to ensure drug dialyzability. ${ }^{42}$ In all release experiments, each dialysis bag was fixed to a 
50-mL glass beaker containing $25 \mathrm{~mL}$ of release medium of sodium phosphate buffer (SPB) with a $\mathrm{pH}$ value of 5.5. The experiment was carried out in a thermostated shaking water bath (Kottermann, type 3047; Hanigsen, Germany) at $32^{\circ} \mathrm{C}$ and $100 \mathrm{rpm}$. Drug solution in PG $(0.5 \mathrm{~mL})$, HPMC-based gel $(0.5 \mathrm{~g})$, and LCG (0.5 g) were added to dialysis bags (Visking 36/32, $28 \mathrm{~mm}$, molecular weight cutoff 12,000-14,000; Serva, Heidelberg, Germany). Then, samples of $3 \mathrm{~mL}$ were withdrawn from release medium at fixed time intervals $(0.5,1.5$, $2.5,4,6,20$, and $24 \mathrm{~h}$ ) and filtered through a membrane filter (Nylon Acrodisc ${ }^{\circledR}, 0.45 \mu$; Gelman Sciences Inc., Ann Arbor, MI, USA). After each sample withdrawal, the same volume of fresh phosphate buffer was added for compensation. All filtrated samples - in triplicates - were measured spectrophotometrically at $227 \mathrm{~nm}$ against blank. Results were represented as percentage release \pm standard error of mean (SEM), and graph of $\%$ drug release versus time was plotted. ${ }^{43}$

\section{Ex vivo permeation studies}

\section{Preparation of skin samples}

Female Wistar albino rats of a weight ranging from 150 to $200 \mathrm{~g}$ were used for the study. All animal work carried out in the current study was approved by the Animal Care and Use Committee (ACUC) at the Faculty of Pharmacy, Alexandria University and was in accordance with the International Principles for Laboratory and Care of the European Community Directive of 1986; 86/609/EEC. The animals were kept under standard laboratory conditions and veterinary supervision with access to water and food ad libitum. The animals were anesthetized by intraperitoneal injection (IP) of thiopental solution (40 mg/kg). ${ }^{44}$ Dorsal hair of the animals was removed using shaving razor in the direction of tail to head, and the animals were then visually inspected to ensure the absence of any skin damage. ${ }^{45}$ The shaven part of skin was separated from animals, and hypodermis was removed with scalpel. ${ }^{40,46}$ The excised skin was washed with normal saline, stored in refrigerator $\left(-20^{\circ} \mathrm{C}\right)$ and used within 1 week of harvest. ${ }^{45,47}$

\section{Permeation studies}

Ex vivo release studies of Tr from lecithin-based LCG and HPMC hydrogel were carried out using modified Franz diffusion cells (surface of $3.14 \mathrm{~cm}^{2}$ and volume $=9 \mathrm{~mL}$ ). ${ }^{26,48}$ The receptor compartment of the Franz diffusion cells was filled with $9 \mathrm{~mL}$ of SPB of $\mathrm{pH} 5.5^{5,41}$ which was suitable for a proper sink condition. The temperature was maintained at $32^{\circ} \mathrm{C} \pm 0.5^{\circ} \mathrm{C}^{8,45,49}$ with shaking at $100 \mathrm{rpm}$ throughout the experiment.

The excited dorsal rat skin was mounted between the donor and the receptor compartments of the diffusion cell where the SC was facing the donor side. ${ }^{50}$ Then the gel preparations were applied uniformly on the membrane at an amount equivalent to $2 \mathrm{mg}$ of drug. A $2 \mathrm{~mL}$ of aliquot was periodically withdrawn at suitable time intervals $(2,4,6$, $8,10,12$, and $24 \mathrm{~h}$ ) from the sampling arm of the receptor chamber and was replaced immediately with fresh release medium. All samples - in triplicates - were filtered through a $0.45 \mu \mathrm{m}$ pore size Teflon membrane filter and analyzed by a validated HPLC method at $227 \mathrm{~nm}$ after appropriate dilutions against blank solution prepared under the same experimental conditions. The percentage of cumulative drug permeated through rat skin was calculated and plotted versus time.

\section{Skin retention study}

At the end of permeation experiments $(24 \mathrm{~h})$, the effective diffusion area of the skin was carefully separated, gently scraped using spatula, and washed with methanol to remove the excess formulations remaining on the skin surface. Skin was then cut into small pieces using a pair of scissors, and all the pieces obtained were vortexed (GEMMY vortex mixer, VM-300; Germany Industrial Corp., Taipei, Taiwan) with methanol. Then samples were left for soaking in methanol for $24 \mathrm{~h}^{45}$ and shaking at $37^{\circ} \mathrm{C}^{5}$ at $100 \mathrm{rpm}$ using thermostated in a water bath to ensure effective extraction of the retained drug from the skin. Then, they were subjected to bath sonication for $1 \mathrm{~h}$, and the resulting mixture was then centrifuged (PLS-5 model; GEMMY Industrial Corp., Taiwan) at $8,000 \mathrm{rpm}^{51}$ for $20 \mathrm{~min}$. The supernatant was then filtered by $0.22 \mu \mathrm{m}$ pore size Teflon membrane filter and was analyzed by a revalidated HPLC method at $243 \mathrm{~nm}$ after suitable dilution. Placebo skin extract was prepared by applying placebo formulations using the same experimental conditions. The placebo extract was set up for the study as blank in order to ensure the absence of interference at the measured wavelength. ${ }^{43}$ The percentage of Tr deposited into the skin and that remained on its surface were calculated and expressed as mean $\pm \operatorname{SEM}(n=3)$.

\section{Reverse phase HPLC (RP-HPLC) analysis}

The concentration of $\operatorname{Tr}$ was determined by a validated HPLC methodology. The HPLC instrument (Agilent 1260 Infinity, Germany) equipped with isocratic pump (G1310B), UV-variable wavelength detector (G1314F) and Agilent ChemStation $^{\circledR}$ software 32-bit version (revision B.02.01 SR1) was used. The mobile phase was composed of a degassed mixture of acetonitrile and potassium dihydrogen phosphate buffer solution (0.01 M, pH 6) with a ratio of 50:50 (v/v). Samples $(20 \mu \mathrm{L})$ were manually injected on a reversed-phase C18 column (Agilent HC-C18 (2), 4.6×250 mm, $5 \mu \mathrm{m}$ ). The flow rate of mobile phase was maintained at $1 \mathrm{~mL} / \mathrm{min}$, and the retention time was $7.07 \pm 0.21 \mathrm{~min}$. Detection of 
amount of $\mathrm{Tr}$ in the receptor medium was performed at $227 \mathrm{~nm}$, while the detection of $\operatorname{Tr}$ deposited in the skin was shifted to another wavelength $(\lambda=243 \mathrm{~nm})$ in order to cancel the interference with the components of skin extract that occurred at $\lambda=227 \mathrm{~nm}$. Concentration of Tr was determined using the corresponding calibration curve constructed by the peak area. The HPLC method was validated at both the detected wavelengths. The method was found to be suitable for $\operatorname{Tr}$ quantification at the selected wavelengths where at $\lambda=227 \mathrm{~nm}$, the calibration curve was linear over the range of $2.5-200 \mu \mathrm{g} / \mathrm{mL}, R^{2}=0.9999$, the precision ( $\left.\% \mathrm{RSD}\right)$ of intra-day and inter-day ranged from $0.06 \%$ to $2.58 \%$ and $0.33 \%$ to $7.91 \%$, respectively, and the accuracy ( $\%$ recovery) of intra-day and inter-day ranged from $91.27 \%$ to $106.18 \%$ and $92.76 \%$ to $103.85 \%$ respectively. While at $\lambda=243 \mathrm{~nm}$, $R^{2}=0.9999, \% \mathrm{RSD}$ of intra-day and inter-day ranged from $0.08 \%$ to $4.91 \%$ and $0.32 \%$ to $12.37 \%$, respectively, and $\%$ recovery of intra-day and inter-day ranged from $94.88 \%$ to $103.44 \%$ and $94.43 \%$ to $101.42 \%$, respectively.

\section{In vivo studies}

\section{In vivo skin deposition study}

The in vivo skin deposition study was carried out for Tr-loaded lecithin-based nanogel formulation $(1 \% \mathrm{w} / \mathrm{w})$ against HPMC hydrogel as was described by Aggarwal et $\mathrm{a}^{8,52}$ with a slight modification. First, female Spargue Dawley rats weighing 250-300 g were anesthetized with an IP of cocktail anesthesia ${ }^{53}$ of ketamine hydrochloride $(80-100 \mathrm{mg} / \mathrm{kg})^{7,54}$ and xylazine $(10 \mathrm{mg} / \mathrm{kg})$. The dorsal skin of rats was shaved using shaving razor in the direction of tail to head and was visually observed to ensure the absence of any skin. Then, a proper weight of LCG and the control (equivalent to $2 \mathrm{mg}$ of $\mathrm{Tr}$ ) were applied on the dorsal prepared region. The animals were divided into five groups for sampling at different time points: $5 \mathrm{~min}, 2 \mathrm{~h}, 4 \mathrm{~h}, 6 \mathrm{~h}$, and $24 \mathrm{~h}$ $(n=4)$. They were sacrificed at the specified time intervals, and the dorsal back skin was excised carefully and washed with methanol to remove the residual formulations on skin surface. Then the skin was prepared as previously described in ex vivo drug retention study in order to extract $\mathrm{Tr}$ deposited on the skin and subsequently analyzed by HPLC under same chromatographic conditions used in ex vivo study.

\section{In vivo antifungal activity of the organogel}

In vivo antifungal activity study was performed according to the method described by Gupta et $\mathrm{al}^{54}$ with slight modifications.

\section{Preparation of the animals}

Female Swiss albino mice, 6-8 weeks of age, were housed in individual cages where food and water were provided ad libitum. An area of $\sim 2 \mathrm{~cm}^{2}$ from each animal's back was shaved $48 \mathrm{~h}$ before infection. In order to establish Candida cutaneous infection, animals were initially immunosuppressed by IP injection of methylprednisolone $(10 \mathrm{mg} / \mathrm{kg}$ of body weight) for three successive days starting $48 \mathrm{~h}$ before infection.

\section{Preparation of Candida and mice infection}

C. albicans (ATCC ${ }^{\circledR}$ 2091) was grown overnight in YPD broth (yeast extract $10 \mathrm{~g} / \mathrm{L}$, peptone $20 \mathrm{~g} / \mathrm{L}$, and dextrose $20 \mathrm{~g} / \mathrm{L}$ ) containing $10 \%$ fetal bovine serum (FBS) for $14-18 \mathrm{~h}$ with vigorous shaking at $30^{\circ} \mathrm{C}$. Next day, the grown culture was subcultured into fresh YPD broth containing 10\% FBS and was further shaken at $37^{\circ} \mathrm{C}$ for $2-3 \mathrm{~h}$. This step converted Candida to the virulent pseudohyphae form which has the ability to establish cutaneous infection. ${ }^{55}$ C. albicans, $3 \times 10^{5} \mathrm{CFU}$ per $50 \mu \mathrm{L}$, was subsequently injected intradermally in the middle of the shaved area of individual mice used to induce infection.

\section{Treatment of fungal infection}

Treatment began $72 \mathrm{~h}$ after the infection was induced where test formulation was topically applied once daily for three consecutive days. Animals were divided into three groups each containing four mice. The first group was treated with liquid crystalline organogel loaded with $\operatorname{Tr}(1 \% \mathrm{w} / \mathrm{w})$. The second group was treated with equivalent dose of Tr HPMCbased hydrogel while the third group served as a control receiving no formulation. All animals were sacrificed $24 \mathrm{~h}$ following the last treatment where the infected skin sites were excised and collected in sterile saline. Each skin sample was homogenized to release $C$. albicans cells from the skin into the sterile saline solution. Then, the skin homogenate was serially diluted in saline and plated onto YPD agar. Plates were incubated for $48 \mathrm{~h}$ at $37^{\circ} \mathrm{C} \pm 1^{\circ} \mathrm{C}$, and then $\mathrm{CFU}$ values were counted..$^{55}$

\section{Skin sensitivity and histological examination studies}

The purpose of these studies was to detect the skin sensitizing and irritant potential of the optimized formulation after topical application. Female Swiss albino mice of 20-25 g were selected for these studies. The negative control group was treated with normal saline ${ }^{45}$ while formalin was used as a standard irritant ${ }^{20,37}$ for the positive control group. The dorsal region of mice was shaved $24 \mathrm{~h}$ prior to the application of the formulations ${ }^{52}$ using a hair remover cream $\left(\right.$ Veet $^{\circledR}$, Reckitt Benchiser). Then, $200 \mathrm{mg}$ of LCG containing $2 \mathrm{mg}$ Tr was applied on the shaved area with uniform spreading once daily for three consecutive days $(n=3)$. The skin was checked for any visible difference, such as erythema after the 
application of formulations for three successive days. The erythemal scores were recorded (ranging from 0 to 4 ) on the basis of the degree of redness as follows: no redness $=0$; slight redness (barely perceptible-light pink) $=1$; moderate redness $($ dark pink $)=2$; moderate to severe redness $($ light red $)=3$; and severe redness (extreme erythema) $=4$ grade. ${ }^{54}$

On the third day, animals were sacrificed, and the skin was cut and processed as reported by Azeem et al. ${ }^{56}$ Briefly, specimens from control groups and the test group were fixed in $10 \%(\mathrm{v} / \mathrm{v})$ buffered formalin. Subsequently, each tissue was rinsed thoroughly with water, dehydrated using a graded series of alcohols, embedded in paraffin wax, and microtomed. Then, the sections were stained with hematoxylin and eosin followed by observation under a high-power light microscope.

\section{Statistical analysis}

Statistical analysis of the results was carried out using analysis of variance (ANOVA) with the level of significance at $P<0.05$ (GraphPad Prism, version 6; GraphPad Software, Inc., La Jolla, CA, USA).

\section{Results and discussion}

The investigated lecithin organogel is composed of lecithin as gelator, nonpolar organic solvent as external phase, and polar solvent that is usually water. Natural lecithin such as Phospholipon $90 \mathrm{G}$ containing not less than $90 \%$ phosphatidylcholine content of unsaturated fatty acids was selected for the organogel preparation. Different oils were screened for their ability to form organogel with the selected lecithin at two mass ratios of 1:1 and 1:2 (lecithin to oil). Among the screened oils, only capryol oil was able to form lecithin organogel at 1:1 mass ratio while others such as Plurol olique ${ }^{\circledR}$ (ployglyceryl-6 diolate), Peceol ${ }^{\circledR}$ (glyceryl mono-oleate), Maisine $35-1{ }^{\circledR}$ (glyceryl monolinoleate), and isopropyl myristate failed to form organogels with lecithin at both the selected ratios.

\section{Construction of ternary phase diagram}

As the phase behavior of PL-oil systems may be influenced by the addition of other compounds, the ratios of lecithin, water, and CAP oil that would lead to the formation of liquid crystals in a gel state at room temperature were first investigated. Ten mixtures were prepared, as depicted in Table 1. Visually, LCG appeared as slight hazy and viscous mixture, ${ }^{57}$ and their structure was confirmed by PLM and transmission electron microscopy (TEM). Among the screened mixtures, only four samples (F1-F4) were able to form LCG. As shown
Table I Composition of LCG constructing phase diagram (lecithin/capryol G90/water)

\begin{tabular}{llllll}
\hline Formula & $\begin{array}{l}\text { G90:CAP } \\
\text { weight ratio }\end{array}$ & $\begin{array}{l}\text { G90 } \\
(\%)\end{array}$ & $\begin{array}{l}\text { CAP } \\
\text { (\%) }\end{array}$ & $\begin{array}{l}\text { Water } \\
(\%)\end{array}$ & $\begin{array}{l}\text { Visual } \\
\text { observation }\end{array}$ \\
\hline FI & $2.3: 1$ & 64.97 & 28.25 & 6.78 & Hazy gel \\
F2 & I.5:I & $42.6 I$ & 28.41 & 28.98 & Hazy gel \\
F3 & I:I & 36.23 & 36.23 & 27.54 & Slight hazy gel \\
F4 & I:I.2 & 33.33 & 40 & 26.67 & Slight hazy gel \\
F5 & I:I.5 & 29.07 & 43.60 & 27.33 & Clear solution \\
F6 & I:2 & 28.35 & 56.68 & 14.97 & Clear solution \\
F7 & I:3 & 20.49 & 61.48 & 18.03 & Clear solution \\
F8 & I:4 & 17 & 68.03 & 14.97 & Clear solution \\
F9 & I:7 & 11.16 & 78.13 & 10.71 & Clear solution \\
FI0 & I:9 & 9.09 & 81.82 & 9.09 & Clear solution \\
\hline
\end{tabular}

Abbreviations: LCG, liquid crystalline nanogel; G90, lecithin; CAP, capryol.

in Table 1, addition of water in a range of $0.3 \%-26.67 \%$, capryol oil in a range of $30.21 \%-40 \%$, and phospholipon $90 \mathrm{G}$ in range of $69.49 \%-33.33 \%$ resulted in the formation of LCG systems. Figure 1 represented the constructed ternary phase diagram of the investigated liquid crystalline system (lecithin/CAP/water). Our target in this study was to prepare stable gel that is able to enhance $\operatorname{Tr}$ skin deposition using the least possible concentration of lecithin in order to produce a commercial product at a reasonable cost. Thus, based on the phase diagram study, a lecithin to oil mass ratio of 1:1.2 was selected for further characterization. In addition, it was believed that organogel system holding the minimal water content would be of choice to avoid $\operatorname{Tr}$ precipitation upon storage due to its hydrophobicity and to maintain the whole system stability. Therefore, a formulation of lecithin to oil mass ratio of $1: 1.2$ comprising $38.46 \%$ lecithin,

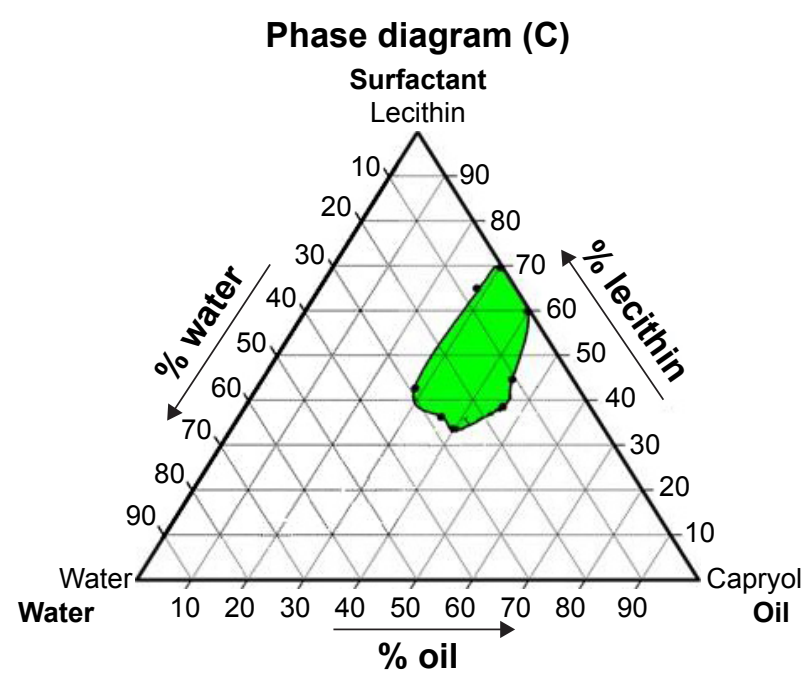

Figure I Ternary phase diagram of the selected system components (lecithin/ capryol 90/water) in weight percentage showing area of LCG.

Abbreviation: LCG, liquid crystalline nanogel. 
$46.16 \%$ capryol, and $15.38 \%$ water was chosen for further characterization. This formulation was given "FC" coding.

\section{Characterization of liquid crystalline organogel \\ Organoleptic characteristics}

Various physical parameters were checked for the chosen formulations. The physical parameters involved color, appearance, smoothness/grittiness, and ease of application. ${ }^{34}$ The selected organogel appeared yellowish, slight hazy, and smooth with no phase separation. The gel was free from any gritty particles and spread easily over the skin. It was slight greasy and tacky upon its application on the skin while after $5 \mathrm{~min}$, the skin has no longer looked greasy or tacky.

\section{$\mathrm{pH}$}

$\mathrm{pH}$ value of the selected formulation was estimated using $\mathrm{pH}$ paper, and it was found to be in a range of 5-6 approximating the normal $\mathrm{pH}$ range of skin. Thus, it was considered as the acceptable range that might help to reduce the irritation produced upon its dermal application. , $^{8,41}$

\section{Viscosity measurements}

For any formulation to be used for topical drug delivery applications, it is essential to study its rheological behavior. Viscosity measurements were determined by applying increasing and decreasing values of shear rate, in order to reveal any possible thixotropic behavior. A plot of shear stress in dyne $/ \mathrm{cm}^{2}$ versus shear rate in $1 /$ second $\left(\mathrm{S}^{-1}\right)$ was constructed where the shear rate was increased up to a certain value and then immediately decreased to the starting point. ${ }^{58}$ As shown in Figure 2, the up and down curves did not completely superimpose on each other, and a hysteresis loop was formed due to the decrease in viscosity of the organogel with increasing shearing time. Thus, rheogram of the tested organogel showed a non-Newtonian pseudo-plastic behavior with a slight thixotropy. ${ }^{59}$

The effect of drug incorporation was investigated in this study where viscosity of both placebo and drug-loaded lecithin organogel samples was determined. It was observed that incorporation of $\mathrm{Tr}$ in liquid crystalline organogel led to insignificant reduction of gel viscosity $(P>0.05)$. At $2 \mathrm{rpm}$, viscosity of Tr-loaded LCG, expressed in mean \pm SEM, was 9.7 \pm 1.60 poise $(n=2)$ while placebo organogel showed $10.01 \pm 1.68$ at the same shear rate. It was reported that drug loading might influence the microstructure of liquid crystalline systems via interaction with curved bicontinuous lipid bilayer of liquid crystalline phase, by making the microstructure became unstable and thus resulting in a phase transformation. ${ }^{60}$ However, the rheological behavior of Tr-loaded LCG revealed that $\mathrm{Tr}$ did not affect the microstructure of LCG significantly.

\section{Drug content uniformity/homogeneity}

The drug content of the studied formulation was evaluated considering the range of $90 \%-110 \%$ of the claimed drug content required for most dosage forms including topical semisolid preparations. ${ }^{61,62}$ Drug content homogeneity of the chosen liquid crystalline organogel was determined by a validated UV spectrophotometric assay at $\lambda=243 \mathrm{~nm}$ ( $\mathrm{y}=0.0263 \mathrm{x}+0.0391, R^{2}=0.9993$, the precision $(\% \mathrm{RSD})$ ranged from $0.10 \%$ to $0.69 \%$ and $0.44 \%$ to $2.13 \%$ for intraday and inter-day, respectively, the accuracy (\% recovery) of intra-day and inter-day ranged from $98.80 \%$ to $101.52 \%$ and $98.48 \%$ to $101.72 \%$, respectively. The drug content was calculated from the calibration curve and expressed as (mean $\% \pm$ standard deviation $[\mathrm{SD}]$ ), $\mathrm{n}=3$ and compared with that obtained from the HPMC hydrogel.

$$
\text { Drug content } \%=\frac{\text { Actual drug content }}{\text { Theoritical drug content }} \times 100
$$

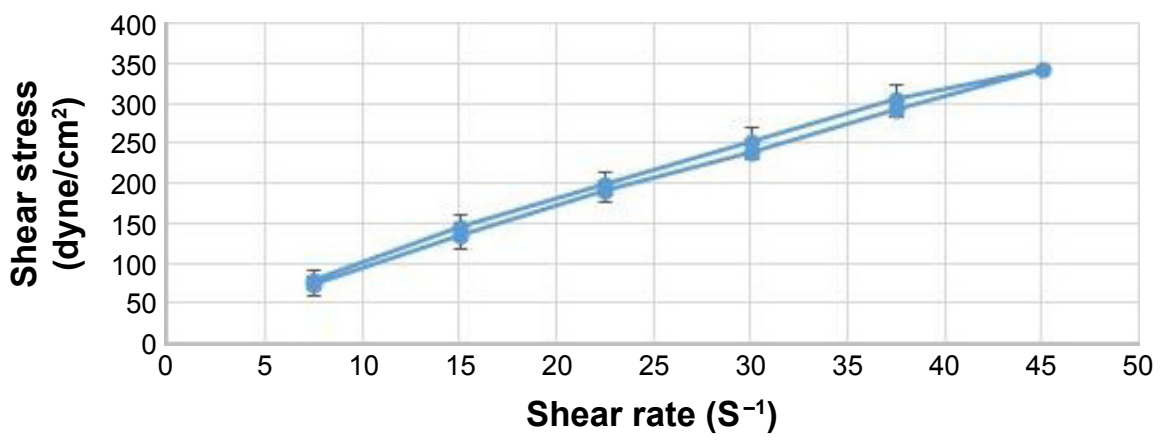

Figure 2 Rheogram showing the pseudoplastic behavior with a slight thixotropy of LCG (FC) loaded with I\% w/w $\operatorname{Tr}$ (constructed by cone and plate viscometer) ( $\mathrm{n}=2$ ). Abbreviations: FC, 38.46\% lecithin, $46.16 \%$ capryol, and 15.38\% water; LCG, liquid crystalline nanogel; Tr, terconazole. 
The results showed that drug content of HPMC hydrogel exceeded the acceptable range (137.43\% $\pm 33.96 \%)$. Thus, it failed to load the drug homogenously throughout its matrix, and this was obviously clear from the high standard deviation of its triplicates. In fact, poor drug distribution through HPMC matrix could be attributed to the hydrophilic nature of the gel, which is considered as an unfavorable environment for hydrophobic drugs; hence, Tr tends to aggregate and form lumps in the gel matrix rather than freely dispersed in. On the other hand, developed lecithin-based organogel showed good homogeneity with acceptable loading efficiency $(110.19 \% \pm 0.24 \%)$ and with the absence of lumps.

\section{Polarizing light microscope evaluation}

The phase behavior of the chosen LCG was confirmed using a polarized light microscope. This technique was applied to identify the hazy systems within the ternary phase diagrams whether they were stable emulsions or LC phases. The anisotropic nature of liquid crystalline system was confirmed under PLM where it showed birefringence due to its molecular organization $^{39}$ as shown in Figure 3.

As there are some parameters such as drug loading and the alteration of the system components proportions could affect the packing parameter of lecithin, thus affecting the prepared liquid crystalline phase, ${ }^{60,63}$ whether drug loading and water capacity would affect the microstructure formed or not was investigated. It was observed that the structure features of the liquid crystals of LCG was not influenced by the

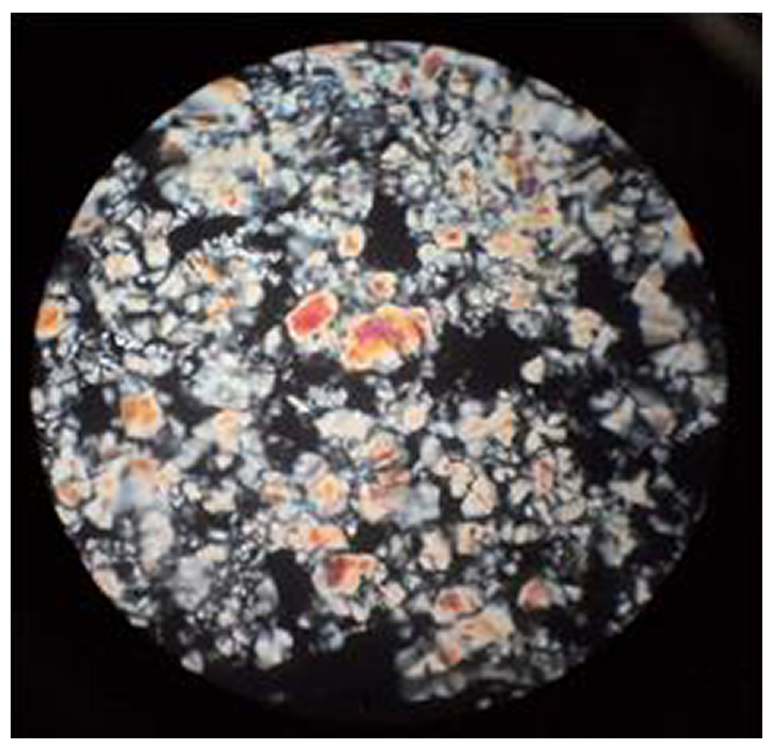

Figure 3 Polarized light microscopy photomicrographs of Tr-loaded LCG (FC) (magnification $\times 100$ ).

Abbreviations: FC, $38.46 \%$ lecithin, $46.16 \%$ capryol, and $15.38 \%$ water; LCG, liquid crystalline nanogel; $\mathrm{Tr}$, terconazole. incorporation of Tr into the system, but it was mainly affected by water content as depicted in Figure 4. Addition of water at the level of $0.90 \%-8.33 \%$ elucidated clear isotropic liquid solution (Figure 4A), which could be due to the formation of isotropic microemulsion or due to the formation of liquid crystals ${ }^{35}$ that were too small to be seen with used magnification $(\times 100)$. Upon increasing water content from $9.09 \%$ to $14.73 \%$ as shown in Figure 4B-D, a hazy liquid dispersion was formed which appeared as small and disaggregated liquid crystals under PLM. At the level of 15.38\%-26.67\%, the viscosity of formulation increase forming a LCG where it showed well-structured liquid crystals under PLM as was elucidated in Figure 3.

\section{TEM}

TEM was performed for the selected Tr-loaded liquid crystalline-based organogel $(1 \% \mathrm{w} / \mathrm{w})$ to confirm morphology and for particle-size analysis. ${ }^{20}$ TEM demonstrated irregular and discrete microstructures for liquid crystalline organogel. The system showed liquid crystals of small particle size $<50 \mathrm{~nm}$ as shown in Figure 5. Small particle size of liquid crystals could be attributed to the surface activity of capryol 90 oil, ${ }^{64-66}$ which could influence the surfactant layer curvature of lecithin, ${ }^{65}$ resulting in the reduction of the size of liquid crystals.

\section{In vitro antifungal activity}

As C. albicans is primarily responsible for various skin infections, it was used in the current study as a reference for the evaluation of in vitro antifungal activity of $\mathrm{Tr}$. The in vitro antifungal activity of Tr against $C$. albicans (ATCC ${ }^{\circledR}$ 2091) was determined in terms of mean diameter of inhibition zone $(\mathrm{mm}) \pm \mathrm{SD}(\mathrm{n}=3)$. Tr-loaded LCG $(1 \% \mathrm{w} / \mathrm{w})$ showed significant higher in vitro antifungal activity $(32.33 \pm 0.88)$ when compared to HPMC hydrogel (29.46 \pm 0.68$), P<0.05$. Surprisingly, this study was the first to reveal that placebo capryol-based formulations possessed an in vitro antifungal activity, where the placebo LCG showed nearly half of the in vitro antifungal activity of its drug-loaded formulation. This may be attributed to physicochemical properties of CAP oil. Capryol oil was reported to have a surface activity acting as nonionic surfactant $t^{64} /$ or cosurfactant $^{65,66}(\mathrm{HLB}=6)$. Nonionic and cationic surfactants were suggested to have antifungal activity due to the inhibition of the steroidal component of the fungi, which forms an integral part of its cell wall by their surface-tension-lowering activity. ${ }^{37,67}$ Moreover, capryol 90 contains $10 \%$ capric acid, which was reported to have antifungal activity. ${ }^{68}$ Therefore, it is worthy to note that 

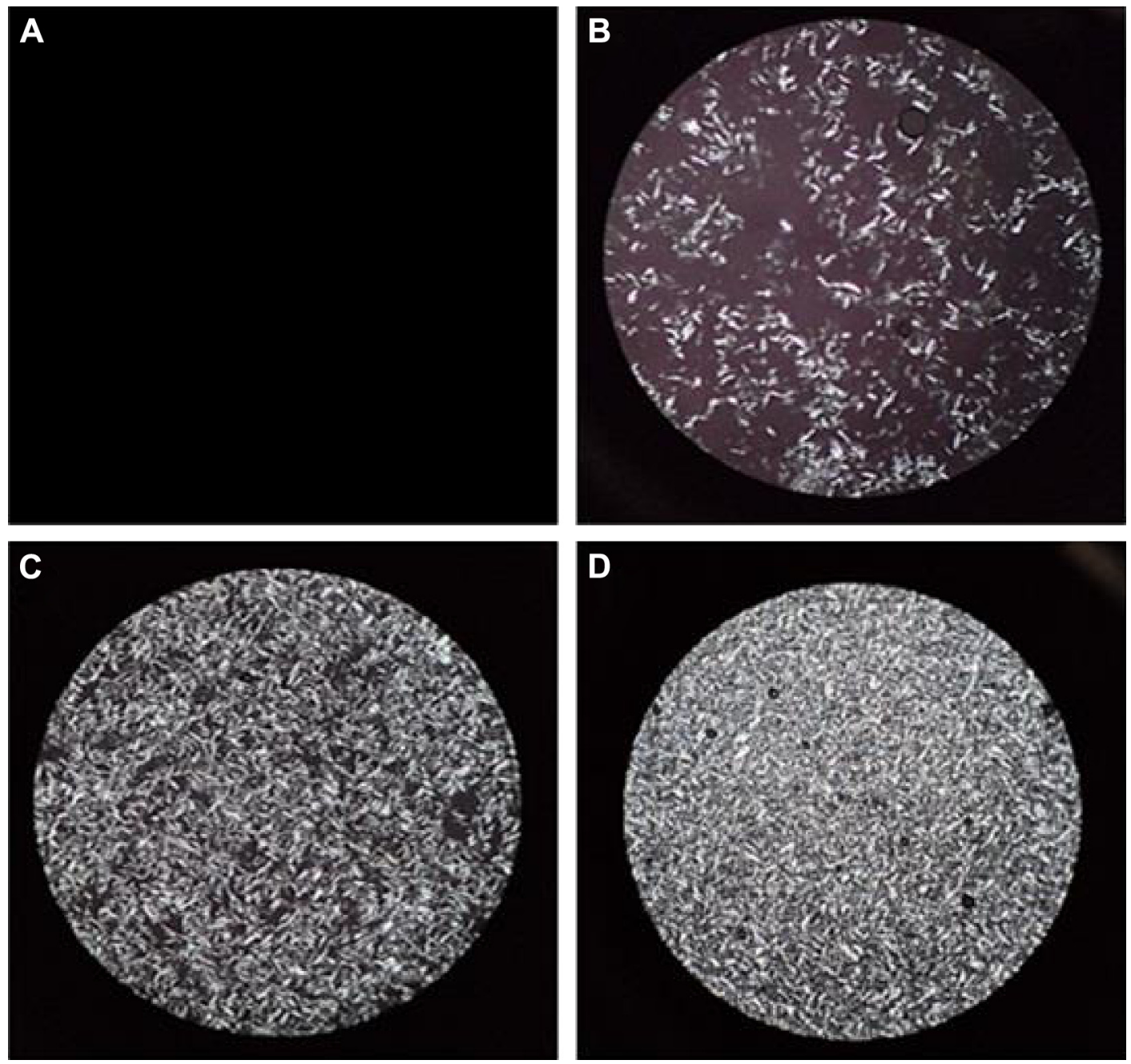

Figure 4 Polarized light microscopy photomicrographs of Tr-loaded LCG (FC) showing the effect of water content on LC formation

Notes: (A) Isotropic system formed at water content of 0.90\%-8.33\%. (B) Low-density LCs at $9.09 \%$ water content. (C) LC density increased at I0.57\%. (D) High-density LCs at $14.73 \%$ water content (magnification $\times 100$ ).

Abbreviations: FC, $38.46 \%$ lecithin, $46.16 \%$ capryol, and $15.38 \%$ water; LCG, liquid crystalline nanogel; Tr, terconazole.

the in vitro antifungal potential of Tr-loaded liquid crystalline organogel was partially due to capryol oil itself. The higher in vitro antifungal activity of $\mathrm{Tr}$ compared to HPMC hydrogel confirmed the enhancement of physicochemical characteristics of Tr upon its incorporation in nanogel system.

\section{In vitro release study}

In vitro release of $\mathrm{Tr}$ from lecithin-based LCG was assessed using dialysis bags with proper molecular weight cutoff value $(12-14,000)$. Solubility study of $\mathrm{Tr}$ in phosphate buffers of different $\mathrm{pH}$ was carried out at $\lambda_{\max }=227 \mathrm{~nm}$. It was found that drug solubility, expressed as mean $\pm \mathrm{SD}(\mathrm{n}=3)$, was significantly decreased with $\mathrm{pH}$ increase $(P<0.05)$. $\mathrm{Tr}$ solubility was lower in phosphate buffer of $\mathrm{pH} 7.4(0.08 \pm 0.01$ $\mathrm{mg} / \mathrm{mL})$ than phosphate buffer of $\mathrm{pH} 5.5(2.75 \pm 0.14 \mathrm{mg} / \mathrm{mL})$. This could be attributed to the basic functional group of the drug (NH-piperazine, pKa 8.7) that tended to be ionized in the acidic environment provided with buffer of $\mathrm{pH}$ 5.5. Consequently, drug release testing was carried out in phosphate buffer of pH 5.5 to attain proper sink condition. ${ }^{69}$ Initial drug strength was unified among all formulations screened to omit the effect of concentration gradient. ${ }^{27}$ Release profiles of Tr from liquid crystalline organogel, HPMC hydrogel, and plain drug solution in PG were performed using the dialysis bag method as shown in Figure 6.

It was clear from the graph that LCG showed a delay in the release rate and also a decrease in the amount of Tr released in comparison with its release from the plain solution and the hydrogel. The percentage of $\operatorname{Tr}(\%)$ released after $24 \mathrm{~h}$ from plain drug solution in PG- and HPMC-based hydrogel was $98.90 \% \pm 2.00 \%$ and $64.77 \% \pm 4.53 \%$, respectively, which was significantly higher than $\mathrm{LCG}(P<0.01)$. As expected, $\mathrm{Tr}$ 


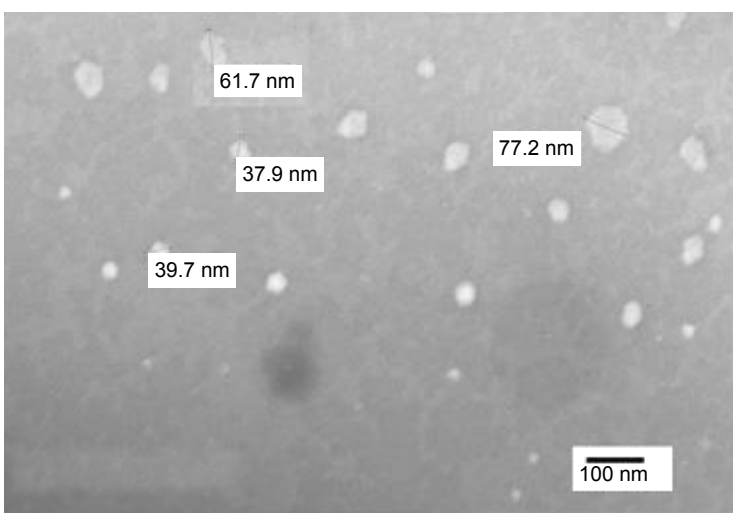

Figure 5 Transmission electron microscopy photograph of lecithin-based LCG (FC) with 10 -fold dilution in capryol (magnification $\times 10,000$ ).

Abbreviations: FC, $38.46 \%$ lecithin, $46.16 \%$ capryol, and $15.38 \%$ water; LCG, liquid crystalline nanogel.

release rate was retarded when it was embedded into hydrophobic gel matrix. ${ }^{49}$ Whereas, the high drug flux from HPMC gel could be attributed to increase its thermodynamic activity through the hydrophilic gel matrix. According to Higuchi, ${ }^{70}$ the flux of a drug through a membrane increases as the drug thermodynamic activity increases. ${ }^{23}$ This can be done either by increasing the drug concentration in the vehicle or by decreasing the drug solubility in the vehicle. ${ }^{71}$ Thus, Tr preferred diffusion through dialysis membrane rather than dispersion in hydrophilic gel unlike in case of PL-based gel.

\section{Ex vivo studies}

\section{Ex vivo permeation study}

Drug penetration into the skin could be enhanced using liquid crystalline phases that have been recently investigated for topical application. ${ }^{36,63,72,73}$ In order to confirm this, comparative ex vivo permeation studies of $\mathrm{Tr}$ were performed from lecithin-based liquid crystalline organogel and HPMC-based hydrogel. The ex vivo release pattern of Tr from each formulation was shown in Figure 7.
The percentage of the cumulative amount of $\mathrm{Tr}$ released in the diffusion medium ( $\mathrm{SPB}$ of $\mathrm{pH}=5.5$ ) at different time intervals was calculated from the calibration curve in SPB and expressed as mean $\% \pm$ SEM as shown in Figure 7. Permeation of $\operatorname{Tr}$ was improved upon its incorporation into organogel matrix as Tr showed nearly twofold increase in its permeation when compared with its permeation from HPMC hydrogel. This could be attributed to the physicochemical characteristics of the organogel components. Both lecithin ${ }^{30,74,75}$ and capryol $90^{\circledR}$ oil $^{76,77}$ were reported as skin penetration enhancer. In addition, perhaps the particle size was one of the parameters that influenced percutaneous permeation of $\mathrm{Tr}^{72}$ The small particle size of the system $(<100 \mathrm{~nm})$ might create a large surface area for the drug to transfer deeply into the skin, thus improving its partition through the skin. Finally, skin penetration and percutaneous delivery of $\operatorname{Tr}$ might also be affected by the interactions of the different liquid crystalline systems with the SC. ${ }^{63,78}$ A comparison between in vitro Tr release and its ex vivo permeation and deposition through rat skin, after $24 \mathrm{~h}$, was shown in Table 2.

\section{Skin retention study}

Skin retention study was carried out to investigate whether the LCG could target Tr into skin layer with a sustained localizing effect or not. Thus, skin samples were collected at the end of permeation study to estimate $\operatorname{Tr}$ percentage deposited in the skin. The amount of Tr retained in the skin was estimated using HPLC technique under the same chromatographic conditions applied in the section of skin permeation study except for the wavelength used for the detection. The amount of $\mathrm{Tr}$ permeated into the release medium was detected at $227 \mathrm{~nm}$, while the deposited amount in the skin was detected at $\lambda=243$ $\mathrm{nm}$ in order to cancel the interference with components of skin extract that appeared at $\lambda=227 \mathrm{~nm}$.

Tr accumulation into the skin was greater than its percutaneous permeation from LCG. This was obviously revealed

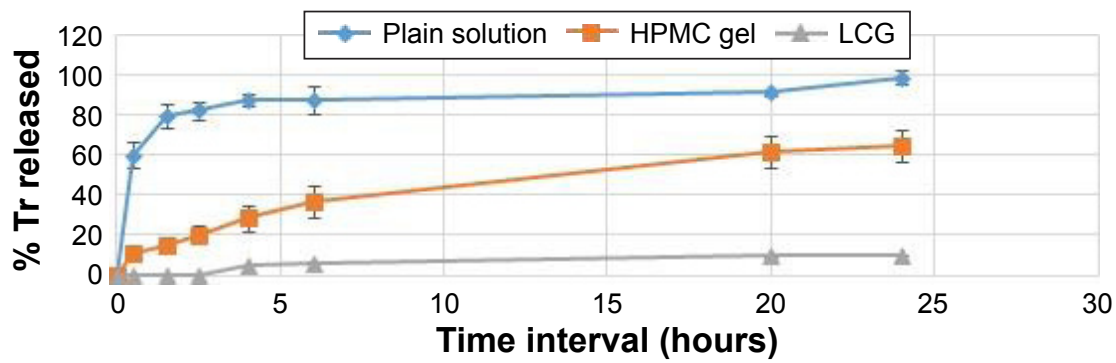

Figure 6 In vitro drug release profile of Tr from different formulations through dialysis bag: LCG (FC), HPMC hydrogel, and plain drug solution in PG. Notes: The values represent mean \pm SEM $(n=3)$. Some error bars are too small to be shown.

Abbreviations: FC, 38.46\% lecithin, $46.16 \%$ capryol, and I5.38\% water; HPMC, hydroxy propyl methyl cellulose; LCG, liquid crystalline nanogel; PG, propylene glycol; SEM, standard error of mean; $\mathrm{Tr}$, terconazole. 


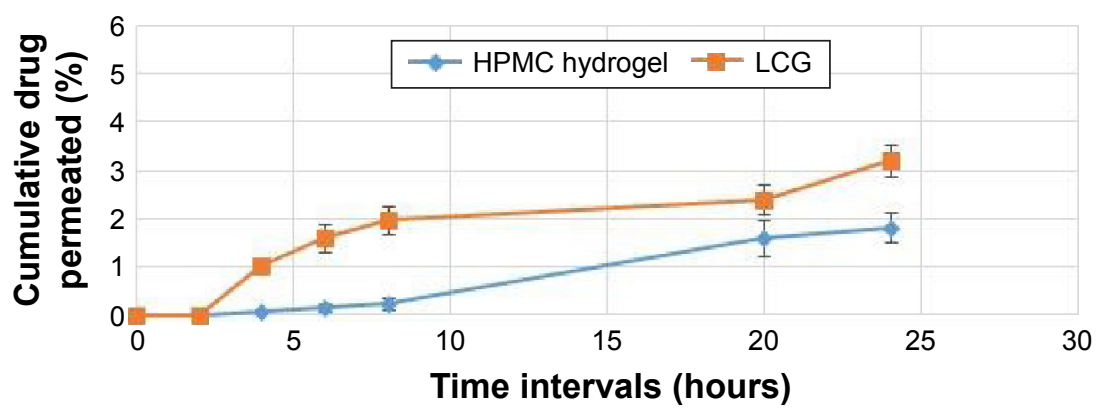

Figure 7 Ex vitro skin permeation of Tr from LCG (FC) against HPMC hydrogel through dorsal skin of rats using the Franz diffusion cell method. Note: The values were expressed as a mean $\pm \operatorname{SEM}(n=3)$.

Abbreviations: FC, 38.46\% lecithin, $46.16 \%$ capryol, and I5.38\% water; HPMC, hydroxy propyl methyl cellulose; LCG, liquid crystalline nanogel; SEM, standard error of mean; $\mathrm{Tr}$, terconazole.

from the results of ex vivo skin retention study given in Table 2 where each point was represented as a mean $\% \pm$ SEM. In addition, LCG showed approximately fivefold significant higher accumulation of $\operatorname{Tr}(P<0.01)$ when compared to HPMC hydrogel. A comparison between the percentage of Tr permeated through the skin and its \% deposited in the skin from LCG against HPMC gel was depicted in Figure 8. The significant enhanced drug deposition from capryol-based LC organogel could be attributed to more than one factor. One of the mechanisms reported for lyotropic liquid crystals (LLCs) was that they demonstrate high similarity to the intercellular lipid membrane of the skin so they might result in good adhesiveness to the skin and good delivery of the drug. ${ }^{35,39,63}$ The LLC systems could also exhibit good penetration, due to the very low interfacial surface tension arising at the oil/water interface, and they may facilitate the progressive diffusion of the drug into the skin. ${ }^{79,80}$ In addition, small particle size of LCs that was probably due to the surface activity of capryol oil (HLB =6) might also increase Tr partitioning into the skin as mentioned earlier. Furthermore, capryol oil could affect $\operatorname{Tr}$ permeation by another mechanism rather than its impact on particle size. Generally, nonionic surfactants were reported

Table 2 In vitro release through dialysis membrane, ex vivo permeation, and ex vivo skin retention studies from LCG- and HPMC-based hydrogel

\begin{tabular}{llll}
\hline $\begin{array}{l}\text { Formulation } \\
\text { code }^{\mathrm{a}}\end{array}$ & $\begin{array}{l}\text { \% Tr released } \\
\text { across } \\
\text { dialysis bag }\end{array}$ & $\begin{array}{l}\text { \% } \\
\text { through the } \\
\text { skinc }^{\mathrm{c}}\end{array}$ & $\begin{array}{l}\text { \% Tr accumulated } \\
\text { into skinc }\end{array}$ \\
\hline LCG & $9.93 \pm 0.21$ & $3.22 \pm 0.34$ & $12.25 \pm 0.40$ \\
HPMC & $64.77 \pm 4.53$ & $1.81 \pm 0.31$ & $2.61 \pm 0.31$ \\
Tr solution $^{\mathrm{b}}$ & $98.90 \pm 2.00$ & - & - \\
\hline
\end{tabular}

Notes: ${ }^{a} A l l$ formulations are loaded with equivalent amount of $\operatorname{Tr}(1 \% \mathrm{w} / \mathrm{w})$. ${ }^{\mathrm{b}} \mathrm{Tr}$ solution in PG was enrolled in in vitro release study to prove its dialyzability. 'The data of the drug released after $24 \mathrm{~h}$ were expressed as $\%$ mean \pm SEM $(n=3)$. Abbreviations: FC, 38.46\% lecithin, $46.16 \%$ capryol, and $15.38 \%$ water; HPMC, hydroxy propyl methyl cellulose; LCG, liquid crystalline nanogel; SEM, standard error of mean; $\mathrm{Tr}$, terconazole. to emulsify sebum and extract skin lipids, thus enhancing the partition of the drug and allowing it to penetrate into the cells more effectively. ${ }^{45}$

\section{In vivo studies}

In vivo skin deposition studies

Liquid crystalline organogel was investigated to assess the proportion of dermal deposition of $\operatorname{Tr}$ at different time intervals. In fact, it is more preferable for a skin targeting formulation to exhibit rapid penetration into the $\mathrm{SC}$ with drug depot properties as suggested by Aggarwal et al. ${ }^{52}$ The results of in vivo skin deposition, representing the amount of Tr retained in the skin (mean $\mu \mathrm{g} \pm \mathrm{SEM}$ ), as shown in Table 3 revealed that lecithin-based liquid crystalline organogel exhibited rapid penetration of Tr into the skin. Where after $5 \mathrm{~min}, \sim 72.1 \pm 1.9 \mu \mathrm{g}$ of $\mathrm{Tr}$ was deposited from LCG into the skin showing 2.4-fold significant increase when compared with its release from HPMC hydrogel $(P<0.01)$. Then the amount of Tr was gradually decreased regardless the formulation used. Yet a significant higher drug deposition was attained from the nanogel in comparison with the hydrogel up to $4 \mathrm{~h}$ post application $(P<0.01)$. Whereas, $6 \mathrm{~h}$ after application, LCG showed 1.4-fold higher increase in Tr skin localization than HPMC gel, but this increase was not significant $(P>0.05)$. However, at later stages $(24 \mathrm{~h})$, LCG showed 2.67-fold increase in $\operatorname{Tr}$ deposition, which was significant $(P<0.05)$ when compared with its deposition from HMPC hydrogel. The differences in Tr skin deposition between LC organogel and HPMC hydrogel could be attributed to various factors such as microstructure of the organogel matrix, penetration enhancing effect of system components, and particle size of liquid crystals of the organogel. The effect of these parameters on skin deposition was mentioned previously in ex vivo retention study. It is worthy to note that there was difference in the results of both ex vivo and 


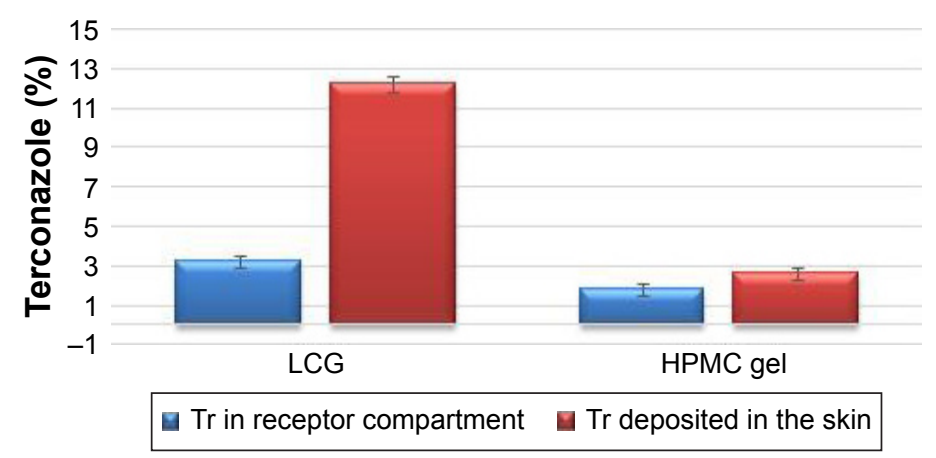

Figure 8 Comparison of the percentage of drug permeation and drug retention from different gel matrices through ex vivo skin permeation studies after $24 \mathrm{~h}$. Abbreviations: HPMC, hydroxy propyl methyl cellulose; LCG, liquid crystalline nanogel; Tr, terconazole; h, hours.

in vivo skin retention studies where ex vivo study revealed $12.25 \% \pm 0.34 \%$ deposition of $\mathrm{Tr}$ in the skin at $24 \mathrm{~h}$ post application. This percentage was much higher than that obtained from in vivo study at all investigated time intervals. This difference could be attributed to the accelerated drug elimination from the skin to the systemic circulation due to the presence of blood supply to the dermis of the rat skin. Although the experimental conditions were different, the results obtained from the in vivo study confirmed our ex vivo observation that lecithin-based organogel system could enhance skin targeting of Tr into the skin much higher than HPMC hydrogel. It is also imperative to notify that the current investigation has focused substantially on cutaneous targeting of Tr into the skin and not on its percutaneous permeation. Consequently, focus was completely on drug deposition in the skin, and no attempt was adopted to analyze its concentration in the blood.

\section{In vivo antifungal activity}

The optimized liquid crystalline organogel containing $1 \% \mathrm{w} / \mathrm{w}$ Tr was assessed for its in vivo antifungal potential against $C$. albicans using female Swiss albino mice in comparison with conventional gel. Induction of fungal infection

Table 3 In vivo skin deposition study representing amount of $\mathrm{Tr}$ deposited in the skin at various time intervals after single topical application of LCG- and HPMC-based hydrogel

\begin{tabular}{lll}
\hline $\begin{array}{l}\text { Time } \\
\text { (hour) }\end{array}$ & \multicolumn{2}{l}{ Formulations $\mathbf{s}^{\mathrm{a}, \mathrm{b}}(\mu \mathrm{g}$ deposited) } \\
\cline { 2 - 3 } LCG & HPMC gel \\
\hline $0.08^{\mathrm{c}}$ & $72.1 \pm 1.9$ & $30 \pm 0.8$ \\
2 & $67.1 \pm 2.8$ & $24.8 \pm 2.8$ \\
4 & $63.1 \pm 1.8$ & $18.4 \pm 8.0$ \\
6 & $24.4 \pm 5.8$ & $17.4 \pm 2.0$ \\
24 & $20.5 \pm 1.5$ & $7.7 \pm 3.9$ \\
\hline
\end{tabular}

Notes: ${ }^{a}$ Both the gels were loaded with equivalent amount of $\operatorname{Tr}(1 \% \mathrm{w} / \mathrm{w}) .{ }^{\mathrm{b}} \mathrm{The}$ data were expressed as mean $\pm \operatorname{SEM}(n=4) .{ }^{c} 0.08 \mathrm{~h}$ is equivalent to $5 \mathrm{~min}$.

Abbreviations: FC, $38.46 \%$ lecithin, $46.16 \%$ capryol, and $15.38 \%$ water; HPMC, hydroxy propyl methyl cellulose; LCG, liquid crystalline nanogel; SEM, standard error of mean; $\mathrm{Tr}$, terconazole. was performed, and the in vivo antifungal activity of LC organogel was assessed through a quantitative analysis of the fungal infection in terms of CFUs found in the skin lesion of infected mice following the treatment course. In vivo microbiological activity of Tr-loaded LCG was compared to HPMC hydrogel loaded with equivalent amount of $\mathrm{Tr}$ (2 mg Tr). Negative control receiving no formulation was also enrolled in the study for comparison. Three days after the treatment course, the mice were sacrificed, each skin sample was homogenized in sterile saline, and C. albicans count was determined. The results are shown in Figure 9. Lecithin organogel showed log CFU of $1.03 \pm 0.35$ while groups receiving HPMC gel and untreated group showed $2.3 \pm 0.12$ and $3.55 \pm 0.04$, respectively. Applying one-way ANOVA test with post hoc Tukey-Kramer test, Tr-loaded lecithin nanogel revealed a significant reduction of the fungal infection after the application for three successive days when compared to the group receiving HPMC gel $(P<0.01)$ and to the group receiving no formulation $(P<0.0001)$. Therefore, in vivo antifungal results were in agreement with the results of both ex vivo and in vivo deposition studies confirming the improvement of physicochemical properties and skin targeting of $\mathrm{Tr}$ after its incorporation in liquid crystalline

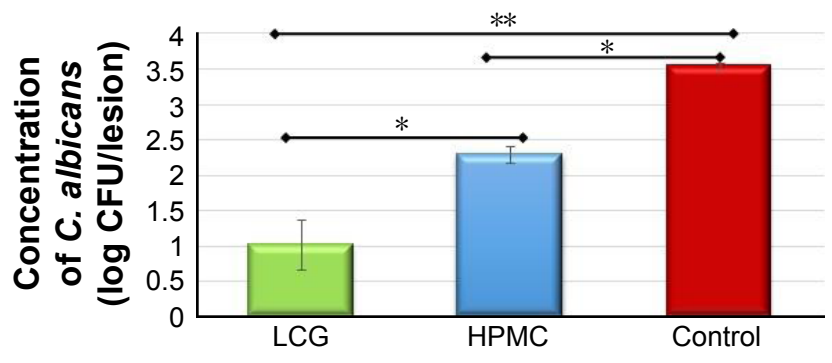

Figure 9 In vivo antifungal efficacy of LCG (FC) as compared to HPMC gel and untreated group (control) after three successive days of single application per day. Notes: Data were expressed as mean \pm SEM $(n=4)$. $* P<0.01$, $* * P<0.0001$.

Abbreviations: C. albicans, Candida albicans; CFU, colony-forming unit; HPMC, hydroxy propyl methyl cellulose; LCG, liquid crystalline nanogel; SEM, standard error of mean. 
organogel matrix. Nanosize of the organogels improved contact and adhesion as well as the use of penetration enhancers, all contributed to the superior effectiveness of LC nanogel over conventional hydrogel.

\section{Skin sensitivity and histological examination studies}

Topical formulation should be evaluated not only in terms of carrier capacity and enhancing drug permeation through the skin but also in terms of its tolerability and toxicity. Liquid crystalline organogels were composed of large amounts of surfactants and oil; hence, it was particularly important to consider the potential skin irritation and toxicological reactions resulting from topical application. The test was carried out for both blank and medicated organogels. The negative control group was treated with normal saline ${ }^{45}$ while formalin was used as a standard irritant ${ }^{20,37}$ for the positive control group.

The skin was observed for any visible change, such as erythema at 24,48 , and $72 \mathrm{~h}$ after the application of formulations. The mean erythemal scores were recorded (ranging from 0 to 4 ) depending on the degree of redness. There was no apparent sign of edema, erythema, papules, wrinkling, or dryness on mice skin 2 days after application of all the formulations including the positive control receiving formalin. However, on the third day severe erythema of grade 4 was appeared on the positive control group and only slight skin dryness and wrinkling appeared on the mice skin receiving other formulations including untreated group receiving saline (Figure 10). Perhaps, skin dryness occurred due to the effect of the depilatory cream and not because of the formulations.

After visual examination of the skin of the animal groups for three consecutive days, the skin specimens were histologically examined to confirm the clinical assessment of skin sensitivity study. Microscopic pictures of the optimized placebo and Tr-loaded organogels, positive control (formalin), and negative control (saline $0.9 \%$ ) were shown in Figure 10A and $\mathrm{B}$. It was observed that skin of negative group treated with saline had a compact SC with closely conjugated corneocytes layer $^{75}$ at high-power lenses $(\times 400)$ (Figure 10D). The skin specimens also showed normal epidermis, dermis, and subcutaneous tissues when observed at low-power lenses $(\times 100)$ under photomicroscope (Optika B-159; Optika Microscopes,
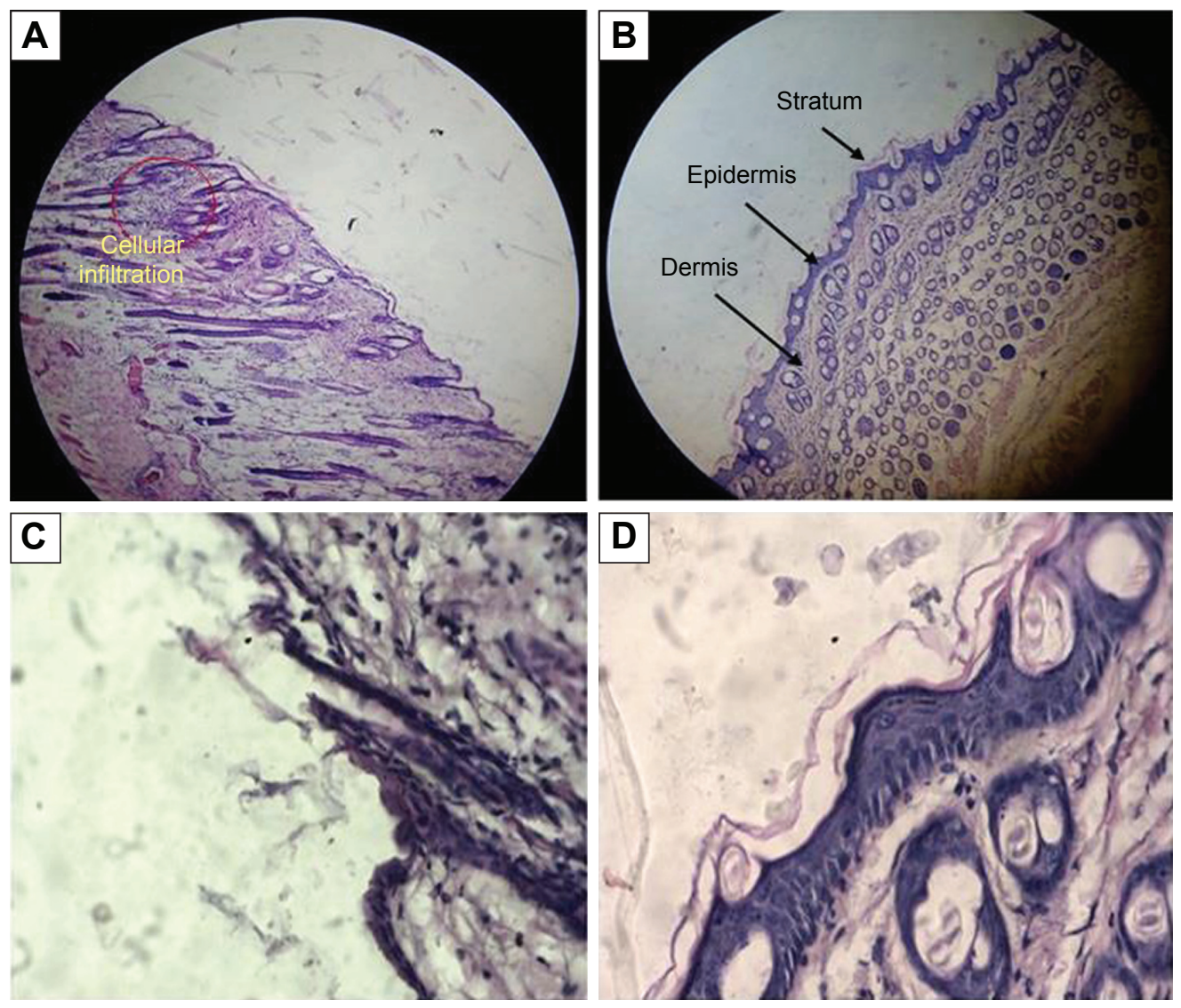

Figure 10 Histological microphotographs of vertical section of mouse skin after hematoxylin and eosin staining.

Notes: (A) Positive control treated with formalin at low-power view $(\times 100)$; (B) negative control treated with saline at low-power view $(\times 100)$; (C) positive control treated with formalin at high-power view $(\times 400)$; (D) negative control treated with saline at high-power view $(\times 400)$. 

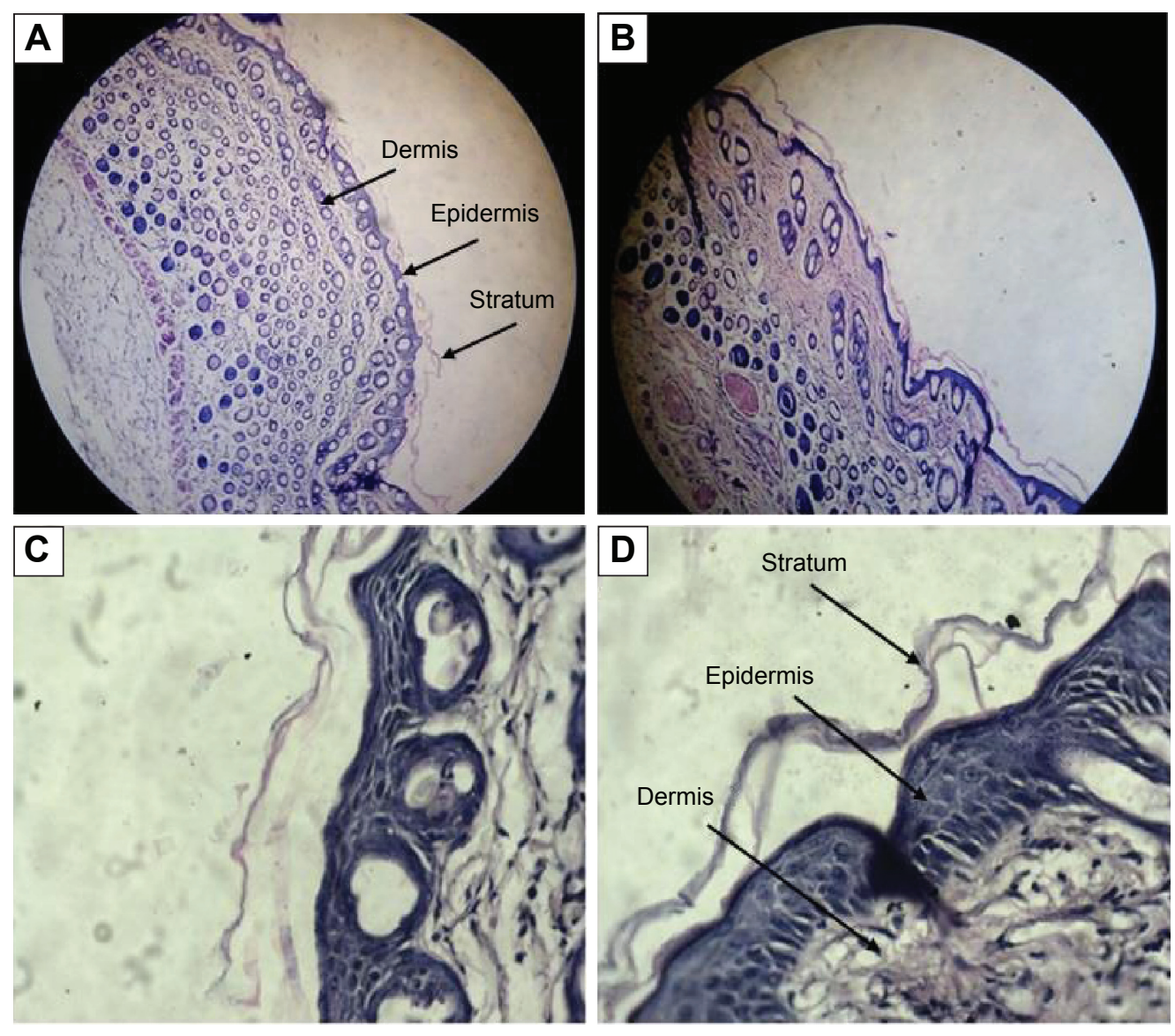

Figure I I Histological microphotographs of vertical section of mouse skin after hematoxylin and eosin staining.

Notes: (A) Skin sample treated with placebo capryol-based LCG (FC) at low-power view $(\times 100)$; (B) skin sample treated with Tr-loaded capryol-based LCG (I\% w/w) at low-power view ( $\times 100)$; (C) skin sample treated with placebo capryol-based LCG at high-power view ( $\times 400)$; (D) skin sample treated with Tr-loaded capryol-based LCG at high-power view $(\times 400)$.

Abbreviations: FC, 38.46\% lecithin, 46.16\% capryol, and 15.38\% water; LCG, liquid crystalline nanogel; Tr, terconazole.

Italy) as shown in Figure 10B. On the other hand, the negative group treated with formalin showed significant change in the histology of the skin. The formalin-treated specimen showed obvious disruption in the $\mathrm{SC}$ organization in addition to the presence of edema and inflammatory cellular infiltration in the dermis (Figures 10A and 11C). The photomicrograph of formalin skin samples along with the apparent signs of skin irritation (severe erythema) observed upon visual examination of the skin specimens confirmed the irritation potential of formalin. ${ }^{56}$

It was worthy to note that the histological samples of the optimized placebo organogel and the medicated gel were nearly similar. They showed skin structure more or less similar to skin treated with the negative control (Figure 11). The dermis layer of the optimized organogels was devoid of any inflammatory cells confirming their nonirritant effect on skin. ${ }^{56}$ Whereas, the application of these nano-based organogels caused a change in the SC where an increase in the overall thickness of the SC was observed at high-power lenses $(\times 400)$ as depicted in Figure $11 \mathrm{C}$ and D, respectively. This might be one of the possible contributing factors by which lecithin nanogels increased the permeation of Tr into the skin. The increase in the thickness of SC could be attributed to the composition of lecithin organogel where lecithin itself could mix and fuse with skin lipids resulting in loosening of the skin structure and disorganization of the lamellar arrangement of the lipids. ${ }^{81,82}$

To conclude, lecithin organogels could weaken the SC barrier and consequently facilitate $\operatorname{Tr}$ permeation through the skin. Moreover, they were considered nonirritant delivery systems according to their visual observation and histological examination of the treated skin samples. Hence, lecithinbased liquid crystalline organogel seemed to be effective and safe nanocarriers for dermal delivery.

\section{Conclusion}

The current study aimed to investigate the relevance of nano-sized lecithin-based liquid crystalline organogel to 
improve the physicochemical characteristics of $\mathrm{Tr}$ in order to implement its dermal application in skin candidiasis. A graphical abstract was designed to summarize the main findings of the whole study. The study revealed that lecithin/ capryol 90/water mixtures were able to form in situ liquid crystalline organogel at certain component ratios as shown in the phase diagram study. The microstructure of LCG was confirmed by PLM and TEM observations where PLM showed a birefringent behavior while TEM images showed discrete and irregular shapes with particle size $<100 \mathrm{~nm}$. A rheological study showed a non-Newtonian behavior with slight thixotropic properties. The results of ex vivo and in vivo skin deposition studies showed that lecithin liquid crystalline organogel could significantly enhance skin targeting of Tr with a skin drug reservoir properties when compared to HPMC hydrogel. The absence of any sign of skin inflammation during the acute irritation study indicated the safety of LCG for dermal drug delivery. In addition, the histological examination revealed a morphological alteration of the SC where its thickness was increased with a loose conjugation of corneocyte layers. This resulted in an increase in the permeation of $\mathrm{Tr}$ into skin dermis.

\section{Disclosure}

The authors report no conflicts of interest in this work.

\section{References}

1. Shao PL, Huang LM, Hsueh PR. Recent advances and challenges in the treatment of invasive fungal infections. Int J Antimicrob Agents. 2007; 30(6):487-495.

2. Pfaller MA, Diekema DJ. Epidemiology of invasive candidiasis: a persistent public health problem. Clin Microbiol Rev. 2007;20(1): 133-163.

3. Dabas PS. An approach to etiology, diagnosis and management of different types of candidiasis. J Yeast Fungal Res. 2013;4(6):63-74.

4. Calzavara-Pinton PG, Venturini M, Sala R. A comprehensive overview of photodynamic therapy in the treatment of superficial fungal infections of the skin. J Photochem Photobiol B Biol. 2005;78(1):1-6.

5. Verma S, Bhardwaj A, Vij M, Bajpai P, Goutam N, Kumar L. Oleic acid vesicles: a new approach for topical delivery of antifungal agent. Artif Cells Nanomed Biotechnol. 2014;42(2):95-101.

6. Zhang Z, Tsai P-C, Ramezanli T, Michniak-Kohn BB. Polymeric nanoparticles-based topical delivery systems for the treatment of dermatological diseases. Wiley Interdiscip Rev Nanomedicine Nanobiotechnology. 2013;5(3):205-218.

7. Gupta M, Goyal AK, Paliwal SR, et al. Development and characterization of effective topical liposomal system for localized treatment of cutaneous candidiasis. J Liposome Res. 2010;20(4):341-350.

8. Aggarwal N, Goindi S. Preparation and evaluation of antifungal efficacy of griseofulvin loaded deformable membrane vesicles in optimized guinea pig model of Microsporum canis-dermatophytosis. Int J Pharm. 2012; 437(1-2):277-287.

9. Kyle AA, Dahl MV. Topical therapy for fungal infections. Am J Clin Dermatol. 2004;5(6):443-451.

10. Zhang AY, Camp WL, Elewski BE. Advances in topical and systemic antifungals. Dermatol Clin. 2007;25(2):165-183.
11. Lewis RE. Current concepts in antifungal pharmacology. Mayo Clin Proc. 2011;86(8):805-817.

12. Maertens JA. History of the development of azole derivatives. Clin Microbiol Infect. 2004;10(1):1-10.

13. Fromtling RA. Overview of medically important antifungal azole derivatives. Clin Microbiol Rev. 1988;1(2):187-217.

14. Sood G, Nyirjesy P, Weitz MV, Chatwani A. Terconazole cream for non-Candida albicans fungal vaginitis: results of a retrospective analysis. Infect Dis Obstet Gynecol. 2000;8(5-6):240-243.

15. Odds FC, Webster CE, Abott AB. Antifungal relative inhibition factors: BAY 1-9139, bifonazole, butoconazole, isoconazole, itraconazole (R 51211), oxiconazole, Ro 14-4767/002, sulconazole, terconazole and vibunazole (BAY n-7133) compared in vitro with nine established antifungal agents. J Antimicrob Chemother. 1984;14:105-114.

16. Cooper CR, McGinnis MR. In vitro susceptibility of clinical yeast isolates to fluconazole and terconazole. Am JObstet Gynecol. 1996;175(6): 1626-1631.

17. Ringdahl EN. Treatment of recurrent vulvovaginal candidiasis. Am Fam Physician. 2000;61(11):3306-3312.

18. Carr PL, Felsenstein D, Friedman RH. Evaluation and management of vaginitis. J Gen Intern Med. 1998;13(5):335-346.

19. Güngör S, Erdal MS, Aksu B. New formulation strategies in topical antifungal therapy. J Cosmet Dermatological Sci Appl. 2013;3(1):56-65.

20. Zakir F, Vaidya B, Goyal AK, Malik B, Vyas SP. Development and characterization of oleic acid vesicles for the topical delivery of fluconazole. Drug Deliv. 2010;17(4):238-248.

21. Benson HA. Transdermal drug delivery: penetration enhancement techniques. Curr Drug Deliv. 2005;2(1):23-33.

22. Prausnitz MR, Langer R. Transdermal drug delivery. Nat Biotechnol. 2008;26(11):1261-1268.

23. Morrow DIJ, Mccarron PA, Woolfson AD, Donnelly RF. Innovative strategies for enhancing topical and transdermal drug delivery. Open Drug Deliv J. 2007;1:36-59.

24. Nair A, Jacob S, Al-Dhubiab B, Attimarad M, Harsha S. Basic considerations in the dermatokinetics of topical formulations. Brazilian J Pharm Sci. 2013;49(3):423-434.

25. Elnaggar YSR, Etman S, Abdelmonsif DA, Abdallah OY. Novel piperine-loaded Tween-integrated monoolein cubosomes as brain-targeted oral nanomedicine in Alzheimer's disease: pharmaceutical, biological, and toxicological studies. Int J Nanomedicine. 2015;10:5459-5473.

26. El-refaie WM, Elnaggar YSR, El-Massik MA, Abdallah OY. Novel Self-assembled, gel-core hyaluosomes for non-invasive management of osteoarthritis: in-vitro optimization, ex-vivo and in-vivo permeation. Pharm Res. 2015;32:2901-2911.

27. Elsheikh MA, Elnaggar YSR, Gohar EY, Abdallah OY. Nanoemulsion liquid preconcentrates for raloxifene hydrochloride: optimization and in vivo appraisal. Int J Nanomedicine. 2012;7:3787-3802.

28. Freag MS, Elnaggar YSR, Abdallah OY. Lyophilized phytosomal nanocarriers as platforms for enhanced diosmin delivery: optimization and ex vivo permeation. Int J Nanomedicine. 2013;8:2385-2397.

29. Elnaggar YSR, El-Massik MA, Abdallah OY. Fabrication, appraisal, and transdermal permeation of sildenafil citrate-loaded nanostructured lipid carriers versus solid lipid nanoparticles. Int J Nanomedicine. 2011;6: 3195-3205.

30. Zhai Y, Zhai G. Advances in lipid-based colloid systems as drug carrier for topic delivery. J Control Release. 2014;193:90-99.

31. Das S, Chaudhury A. Recent advances in lipid nanoparticle formulations with solid matrix for oral drug delivery. AAPS PharmSciTech. 2011;12(1):62-76.

32. Attama AA, Momoh MA, Builders PF. Lipid nanoparticulate drug delivery systems: a revolution in dosage form design and development. In: Demir Sezer A. Recent Adv Novel Drug Carrier Syst. 2012:107-140.

33. Omray LK. Liquid crystals as novel vesicular delivery system: a review. Curr Trends Technol Sci. 2013;2(5):347-353.

34. Nesseem DI. Formulation and evaluation of itraconazole via liquid crystal for topical delivery system. J Pharm Biomed Anal. 2001;26(3): 387-399. 
35. Gosenca M, Bešter-Rogač $M$, Gašperlin $M$. Lecithin based lamellar liquid crystals as a physiologically acceptable dermal delivery system for ascorbyl palmitate. Eur J Pharm Sci. 2013;50(1):114-122.

36. Lopes LB, Speretta FFF, Bentley MVLB. Enhancement of skin penetration of vitamin $\mathrm{K}$ using monoolein-based liquid crystalline systems. Eur J Pharm Sci. 2007;32(3):209-215.

37. Wavikar P, Vavia P. Nanolipidgel for enhanced skin deposition and improved antifungal activity. AAPS PharmSciTech. 2013;14(1): 222-233.

38. Kumar J, Muralidharan S, Parasuraman S. Evaluation of antifungal activity of sustained release microsponge enriched fluconazole gel for penile candidiasis in male rats. Int J PharmTech Res. 2014;6(6):1888-1897.

39. Chorilli M, Prestes PS, Rigon RB, et al. Structural characterization and in vivo evaluation of retinyl palmitate in non-ionic lamellar liquid crystalline system. Colloids Surf B Biointerfaces. 2011;85(2):182-188.

40. Ozcan I, Abaci O, Uztan AH, et al. Enhanced topical delivery of terbinafine hydrochloride with chitosan hydrogels. AAPS PharmSciTech. 2009;10(3):1024-1031.

41. Kumar L, Verma S, Jamwal S, Vaidya S, Vaidya B. Polymeric microparticles-based formulation for the eradication of cutaneous candidiasis: development and characterization. Pharm Dev Technol. 2014;19(3): 318-325.

42. Elmoslemany RM, Abdallah OY, El-Khordagui LK, Khalafallah NM. Propylene glycol liposomes as a topical delivery system for miconazole nitrate: comparison with conventional liposomes. AAPS PharmSciTech. 2012;13(2):723-731.

43. Vaghasiya H, Kumar A, Sawant K. Development of solid lipid nanoparticles based controlled release system for topical delivery of terbinafine hydrochloride. Eur J Pharm Sci. 2013;49(2):311-322.

44. IACUC Faculty and Staff. Guideline on anesthesia and analgesia in laboratory animals. University of South Florida; $1-20$. Available from: https:// www.scribd.com/document/250122043/Guidelines-on-Anesthesia-andAnalgesia-in-Laboratory-Animals. Accessed September 1, 2016.

45. Butani D, Yewale C, Misra A. Amphotericin B topical microemulsion: formulation, characterization and evaluation. Colloids Surf B Biointerfaces. 2014;116:351-358.

46. Shishu, Aggarwal N. Preparation of hydrogels of griseofulvin for dermal application. Int J Pharm. 2006;326(1-2):20-24.

47. Sahoo S, Pani NR, Sahoo SK. Microemulsion based topical hydrogel of sertaconazole: formulation, characterization and evaluation. Colloids Surf B Biointerfaces. 2014;120:193-199.

48. El-Refaie WM, Elnaggar YSR, El-Massik MA, Abdallah OY. Novel curcumin-loaded gel-core hyaluosomes with promising burn-wound healing potential: development, in-vitro appraisal and in-vivo studies. Int J Pharm. 2015;486(1-2):88-98.

49. Song SH, Lee KM, Kang JB, Lee SG, Kang MJ, Choi YW. Improved skin delivery of voriconazole with a nanostructured lipid carrier-based hydrogel formulation. Chem Pharm Bull. 2014;62(8):793-798.

50. Song CK, Balakrishnan P, Shim CK, Chung SJ, Chong S, Kim DD. A novel vesicular carrier, transethosome, for enhanced skin delivery of voriconazole: characterization and in vitro/in vivo evaluation. Colloids Surf B Biointerfaces. 2012;92:299-304.

51. Ge S, Lin Y, Lu H, et al. Percutaneous delivery of econazole using microemulsion as vehicle: formulation, evaluation and vesicle-skin interaction. Int J Pharm. 2014;465:120-131.

52. Aggarwal N, Goindi S. Dermatopharmacokinetic and pharmacodynamic evaluation of ethosomes of griseofulvin designed for dermal delivery. J Nanoparticle Res. 2013;15(10):1983.

53. Altuntas A, Yilmaz HR, Altuntas A, et al. Caffeic Acid Phenethyl Ester Protects against Amphotericin B Induced Nephrotoxicity in Rat Model. Biomed Res Int. 2014;2014:1-8.

54. Gupta M, Vyas SP. Development, characterization and in vivo assessment of effective lipidic nanoparticles for dermal delivery of fluconazole against cutaneous candidiasis. Chem Phys Lipids. 2012;165(4):454-461.

55. Conti HR, Huppler AR, Whibley N, Gaffen SL. Animal models for candidiasis. Curr Protoc Immunol. 2014;105:1-17.
56. Azeem A, Talegaonkar S, Negi LM, Ahmad FJ, Khar RK, Iqbal Z. Oil based nanocarrier system for transdermal delivery of ropinirole: a mechanistic, pharmacokinetic and biochemical investigation. Int $J$ Pharm. 2012;422(1-2):436-444.

57. Sahle FF, Metz H, Wohlrab J, Neubert RHH. Lecithin-based microemulsions for targeted delivery of ceramide AP into the stratum corneum: formulation, characterizations, and in vitro release and penetration studies. Pharm Res. 2013;30:538-551.

58. Nasseri A, Aboofazeli R, Zia H, Needham T. Lecithin stabilized microemulsion based organogels for topical application of ketorlac tromethamine. II. In vitro release study. Iran J Pharm Res. 2003;2(2): $117-123$.

59. Malkin A, Isayev AI. Rheology: Concepts, Methods \& Applications. 2nd ed.; 2012:127-221.

60. Vicentini FTMC, Casagrande R, Verri WA, Georgetti SR, Bentley MVLB, Fonseca MJ V. Quercetin in lyotropic liquid crystalline formulations: physical, chemical and functional stability. AAPS PharmSciTech. 2008;9(2):591-596.

61. Coneac G, Vlaia V, Olariu I, et al. Development and evaluation of new microemulsion-based hydrogel formulations for topical delivery of fluconazole. AAPS PharmSciTech. 2015;16(4):889-904.

62. Olariu I, Coneac G, Vlaia L, et al. Development and evaluation of microemulsion-based hydrogel formulations for topical delivery of propranolol hydrochloride. Dig J Nanomater Biostructures. 2014; 9(1):395-412.

63. Lopes LB, Lopes JLC, Oliveira DCR, et al. Liquid crystalline phases of monoolein and water for topical delivery of cyclosporin A: characterization and study of in vitro and in vivo delivery. Eur J Pharm Biopharm. 2006; 63(2):146-155.

64. Shukla JB, Patel SJ. Formulation and evaluation of self micro emulsifying system of candesartan cilexetil. Int J Pharm Pharm Sci. 2010; 2(4):2-5.

65. Serajuddin ATM. Enhanced microemulsion formation in lipid-based drug delivery systems by combining mono-esters of medium-chain fatty acids with di- or tri-esters. $J$ Excipients Food Chem. 2012;3(2): $29-44$.

66. Moghimipour E, Salimi A, Karami M, Isazadeh S. Preparation and characterization of dexamethasone microemulsion based on pseudoternary phase diagram. Jundishapur J Nat Pharm Prod. 2013;8(3):105-112.

67. Mccarron P, Donnelly R, Marouf W, Calvert D. Anti-adherent and antifungal activities of surfactant-coated poly(ethylcyanoacrylate) nanoparticles. Int J Pharm. 2007;340(1-2):182-190.

68. Bergsson G, Arnfinnsson J, Arnfinnsson H. In vitro killing of Candida albicans by fatty acids and monoglycerides. Antimicrob Agents Chemother. 2001;45(11):3209-3212.

69. Elnaggar YSR, El-Massik MA, Abdallah OY. Sildenafil citrate nanoemulsion vs self-nanoemulsifying delivery systems: rational development and transdermal permeation. Int J Nanotechnol. 2011; 8(8/9):749-763.

70. Higuchi T. Physical chemical analysis of percutaneous absorption process from creams and ointments. $J$ Soc Cosmet Chem. 1960;11(2):85-97.

71. Moser K, Kriwet K, Naik A, Kalia YN, Guy RH. Passive skin penetration enhancement and its quantification in vitro. Eur J Pharm Biopharm. 2001;52(2):103-112.

72. Madheswaran T, Baskaran R, Yong CS, Yoo BK. Enhanced topical delivery of finasteride using glyceryl monooleate-based liquid crystalline nanoparticles stabilized by cremophor surfactants. AAPS PharmSciTech. 2013;15(1):44-51.

73. Luo M, Shen Q, Chen J. Transdermal delivery of paeonol using cubic gel and microemulsion gel. Int J Nanomedicine. 2011;6:1603-1610.

74. Valenta C, Wanka M, Heidlas J. Evaluation of novel soya-lecithin formulations for dermal use containing ketoprofen as a model drug. $J$ Control Release. 2000;63(1-2):165-173.

75. Tan Q, Liu W, Guo C, Zhai G. Preparation and evaluation of quercetinloaded lecithin-chitosan nanoparticles for topical delivery. Int $J$ Nanomedicine. 2011;6:1621-1630. 
76. Azeem A, Ahmad FJ, Khar RK, Talegaonkar S. Nanocarrier for the transdermal delivery of an antiparkinsonian drug. AAPS PharmSciTech. 2009;10(4):1093-1103.

77. Lou H, Qiu N, Crill C, Helms R, Almoazen H. Development of w/o microemulsion for transdermal delivery of iodide ions. AAPS PharmSciTech. 2013;14(1):168-176.

78. Stoye I, Schroder K, Muller-Goymann CC. Transformation of a liposomal dispersion containing ibuprofen lysinate and phospholipids into mixed micelles - Physico-chemical characterization and influence on drug permeation through excised human stratum corneum. Eur J Pharm Biopharm. 1998;46(2):191-200.

79. Makai M, Csányi E, Németh Z, Pálinkás J, Erős I. Structure and drug release of lamellar liquid crystals containing glycerol. Int J Pharm. 2003; 256(1-2):95-107.
80. Swarbrick J, Siverly JR. The influence of liquid crystalline phases on drug percutaneous absorption. II. Permeation studies through excised human skin. Pharm Res. 1992;9(12):1550-1555.

81. El Maghraby GM, Barry BW, Williams AC. Liposomes and skin: from drug delivery to model membranes. Eur J Pharm Sci. 2008;34(4-5): 203-222.

82. Lv Q, Yu A, Xi Y, et al. Development and evaluation of penciclovirloaded solid lipid nanoparticles for topical delivery. Int J Pharm. 2009; 372(1-2):191-198.
International Journal of Nanomedicine

\section{Publish your work in this journal}

The International Journal of Nanomedicine is an international, peerreviewed journal focusing on the application of nanotechnology in diagnostics, therapeutics, and drug delivery systems throughout the biomedical field. This journal is indexed on PubMed Central, MedLine, CAS, SciSearch ${ }^{\circledR}$, Current Contents ${ } /$ Clinical Medicine,

\section{Dovepress}

Journal Citation Reports/Science Edition, EMBase, Scopus and the Elsevier Bibliographic databases. The manuscript management system is completely online and includes a very quick and fair peer-review system, which is all easy to use. Visit http://www.dovepress.com/ testimonials.php to read real quotes from published authors.

Submit your manuscript here: http://www.dovepress.com/international-journal-of-nanomedicine-journal 